\title{
Silence, pleasure and agency: sexuality of unmarried girls in Dakar, Senegal
}

\author{
Anouka van Eerdewijk
}

Published online: 5 February 2009

C The Author(s) 2009. This article is published with open access at Springerlink.com

\begin{abstract}
The article investigates the way unmarried Muslim girls in contemporary Dakar construct their sexuality. It explores in what way and to what extent female sexuality is being silenced, and if any, in what way pleasure and sexual agency are present in the narratives of those girls about their intimate lives. Such an analysis is called for in relation to understanding young people's safe sex practices and concerns about reproductive health and HIV/AIDS. Women's own experiences and understandings are often downplayed in studies that focus on and reproduce the dominant discourse of patriarchal control. This article shows the silencing in a malecentered construction of pre-marital sexuality in Dakar, but also reveals female pleasure and sexual agency. This multi-dimensional understanding of female sexuality of Muslim girls in Senegal provides a more dynamic insight of the power processes surrounding safe sex practices.
\end{abstract}

Keywords Senegal $\cdot$ Girls $\cdot$ Sexuality $\cdot$ Virginity $\cdot$ Agency $\cdot$ Women

Senegal is a predominantly Islamic society with $94 \%$ of its population being Muslim. Four percent of the population is Catholic, and two percent is categorised as 'other religions and animism' (EDS-III 1997: 2). Islamic expansion in Senegal began in the nineteenth century, at the same time that the French presence in the region grew. Although the relationship between Islamic leaders and the colonial nation state has been ambiguous - varying from accommodation to resistance - 'for many of the people, Islam appeared as a useful antidote to the pressures of an alien, French culture' (Ingham 1990: 117). As a monotheistic religion, Islam has functioned as a unifying force in Senegal, 'de-ethnicitizing' society by making the belief in one single god the most important connection between people (Diouf 1998: 111-123). Being profoundly Muslim, Senegal should, however, not be seen as an Arab culture,

\footnotetext{
A. van Eerdewijk ( $\square)$

Centre for International Development Issues Nijmegen (CIDIN), Radboud University Nijmegen, Th. v. Aquinostraat 4, P.O. Box 9104, 6500 HE Nijmegen, The Netherlands

e-mail: a.vaneerdewijk@maw.ru.nl
} 
as Islamic and Christian practices have mingled with traditional practices that have a long history in the country's territory.

I conducted fieldwork in Dakar, the capital of Senegal, in order to gain insight into how young people protect themselves against unwanted pregnancies and sexually transmitted infections (STIs), including HIV. In many countries, unmarried young people find themselves in a paradoxical situation where they are not supposed to be sexually active, but at the same time are exposed to unwanted pregnancies and STIs. I was interested in investigating how safe sex practices, or the lack thereof, are embedded in the way the gendered sexualities of unmarried girls and boys are constructed. This article deals with a part of this study: the construction of female pre-marital sexuality in the lived experiences of unmarried girls in Dakar.

Feminist writings on women's sexuality have often addressed the 'repression of women's sexual agency' and 'women's lack of negotiating power' in heterosex (Shefer and Foster 2001: 375). With respect to the sexuality of girls and women in Africa, it is common to read statements that women have a disadvantaged status and position and lack control compared to men (e.g. Green et al. 2001). A well known study in the United Kingdom (Holland et al. 1998) analyses how men's sexuality is constructed as active and focusing on lust and sex, whereas women's sexuality is produced as passive and organized around the need for relationships and love. It is argued that these gendered and heterosexualized patterns of behaviour exclude women's sexual pleasure and limit their ability to practice, negotiate and insist on safe sex.

With the growing attention for sexual and reproductive health issues and in particular HIV, the study of sexuality was rediscovered. Unfortunately, sexuality was often not properly conceptualized in policy-oriented research on reproductive health and HIV/AIDS that was dominated by bio-medical and behaviouralist approaches. Consequently, sexuality became either a normative category or was seen as a problematic factor in relation to unwanted pregnancies or HIV infections. Moreover, a generally flawed gender analysis has led to gender stereotyping in family planning and AIDS prevention campaigns:

In the context of AIDS just as in the one of birth control, it seems [...] as if there is a need to protect women from the sexuality of men and to consider technical solutions as the best means to reach that point. Women are presented as being responsible for protection, whereas their sexual desire is rarely refered to, and heterosexual men as always being 'absent' or hopelessly irresponsable.

(Spencer 2000: 128, translation mine)

The one-dimensional analyses which mainly reproduce dominant discourse on female sexuality, but fail to take into account the multi-layeredness of gendered sexuality are not only problematic in relation to policies, but also in a theoretical sense. When feminist analysis focuses only on patriarchal control, without concentrating on creativity, diversity and empowerment, it reinforces the heteronormative and gendered values it seeks to challenge (Hoskins 2000; Nencel 2004). An emphasis on oppression and danger can lead to the ignorance of women's own experiences and their understandings of agency and choice. In order to do justice to variety and fluidity, an analysis of gendered sexuality has to address both the dominant and sub-dominant dimensions. This article aims to do that by looking at the experiences of unmarried Muslim girls in Dakar. Such an exercise is particularly 
relevant, given the danger of ethnocentrism of western scholars vis-à-vis 'the East' Senegal obviously takes an interesting position in such a debate, as it is not an Arabic Muslim society. In order to avoid the ethnocentric risk of obscuring the heterogeneity of reality by focusing on abstractions rather than actual social relations, the experiences of Dakarois girls in their intimate relationships, as well as the way they speak about this, are the core of this article.

The central question concerns the way in which female pre-marital sexuality is constructed in contemporary Dakar. My interest is to investigate in what way and to what extent female sexuality is being silenced, and if any, in what way pleasure and sexual agency are present in the narratives of those girls. Put differently, I intend to unpack the multi-dimensional reality of the paradoxical situation that those girls live in. I start with looking into the normative context by discussing the practice of the wedding night and the importance of virginity. The section "Virginity and the wedding night" shows the workings of that virginity norm in the way unmarried girls talk about their intimate lives. The statistical figures discussed in the section "What girls do not talk about" show that the norm of virginity is not lived up to by all girls, and this acknowledgement opens up space to investigate questions of pleasure and female agency. In the section "Hypothetical case", girls do speak of sex when asked to react to a hypothetical story, but their explanations for girls' sexual activity remain phrased in negative, and hence silencing, terms. The section "The Glimpses of pleasure" unravels cracks in the surface of the dominant silencing discourse on female pre-marital sexuality. In the section "Silence, pleasure and agency", I reflect on the significance of those cracks, and come to an overall analysis of how silence, pleasure and agency are part of the way female pre-marital sexuality is constructed in contemporary Dakar. I start however with some methodological considerations in the following section.

\section{Talking about sex in the field}

This article draws from fieldwork conducted among 47 girls and boys living in Dakar in 2000/2001. They were all unmarried, and varied in age from 16 to 23. Twenty five girls participated in focus group discussions and 16 girls were interviewed individually. Sampling was done on the basis of schooling and place of residence, as these seemed to be the most influential factors in the socio-economic living conditions of youth in the lower and low-middle income classes. Four sites were selected in order to grasp the diversity of young people in those classes: (1) a public school in Dakar, (2) a public school in the suburbs, (3) a centre for out-of-school youth in Dakar, and (4) a centre for out-of-school youth in the suburbs. ${ }^{1}$ In addition, interviews were conducted with two teenage mothers. The ethnic backgrounds of the interviewees varied, but all but one were Muslim. In the context of the already mentioned Islamization as well as the youth sub-culture, ethnicity did not feature as a major marker of difference for the young people, and has not been taken up as an axis of analysis.

The focus group discussions varied in size from three to nine participants, and on average took 1.5 to 2 hours. They addressed issues of adolescence, gender, love, sex,

\footnotetext{
${ }^{1}$ Private schools were excluded from the sample.
} 
reproductive health concerns, and safe sex practices in a semi-structured manner. The individual interviews were conducted at a later stage, and lasted approximately one hour. They focused on the individual experiences of intimate relationships. All discussions and interviews were conducted in either French or local vernacular (Wolof), and have been realized with the help of a research assistant (for more details, see van Eerdewijk 2007).

The analysis provided below is based on transcriptions of these interviews and group discussions. I concentrate on how Dakarois girls themselves talk about their sexuality. Even though the concern is with girls and their sexuality, the analysis in this article also includes material from interviews and discussions with Dakarois boys. The question of the construction of female pre-marital sexuality can only be understood in relation to the dynamics of boys' sexuality. Yet, the focus here is not on the dynamics between girls and boys as such, but on the silencing of girls' sexuality and the space for female desire, pleasure and agency. An analysis of the gendered power dynamics between girls and boys as such is beyond the scope of this paper: it would depart from other questions and require another analysis. I have elaborated on the norms boys embody and negotiate elsewhere (van Eerdewijk 2005). A condensed analysis of the construction of male pre-marital sexuality is incorporated here in as far as it adds to investigating the pleasure and agency for girls in the context of the silencing of their sexuality.

Speech takes a central place in my analysis, because language is not simply a vehicle to talk about struggles of domination, rather 'language is the site where those struggles are acted out' (Mills 1997: 42-43). The use of quotes from individual girls might suggest that the way they perceive their sexuality is an individual matter, and that these ideas cannot be generalized. However, meaning is not something that individuals construct in a vacuum. On the contrary, meanings and representations that individuals express are part of a larger cultural whole: their narratives are built from inherited resources and come into being under circumstances that are not of their own choosing. The meanings and constructions that individual girls evoke are thus representations of female pre-marital sexuality in society. Analysing their narratives can shed light on such patterns.

\section{Virginity and the wedding night}

In contemporary Dakar, being young has to be understood as the stage between childhood and adulthood. Young people are in a transition from a child, that has to be looked after, to an adult, who is (more or less) independent and can take responsibility. Adolescence is not so much a biologically distinguishable life phase, but a social category. It emerged in Senegal in the context of urbanization and education (Diop 1995; Havard 2001). In the young people's narratives, marriage is a major marker that differentiates a youth from an adult. It is in marriage that young people become adults, take full responsibility and become independent. The way in which marriage constructs adulthood is highly gendered though: for girls, getting married and setting up a home has high priority, whereas for boys getting a job and being successful in life is more important. The terms in Wolof also reveal this. A jànq is a physically mature but not married girl, while jeek is the term used for adult 
married women. A jànq is by definition a virgin, and a jeek by definition not. For men, the terms waxambaane and mag are used to distinguish between non-adults and adults. The difference between the two lies in the capability of the boy to manage his own life. He does not by definition have to be married in order to be considered a man. That does not completely dismiss the importance of marriage in male adulthood, but does imply that boys can follow multiple trajectories in their transition to adulthood, whereas for girls, marriage takes up a key position.

As marriage organizes sexuality, the way adulthood is linked to marriage makes that both adulthood and adolescence come to be defined in terms of sexuality. In Senegal, sex is limited to the institution of marriage; it is only allowed between wife and husband, and should not take place before nor outside marriage. The virginity norm is promoted in a combination of traditional customs and religious beliefs, both Islamic and Christian. ${ }^{2}$ Although the exact values and practices might differ, the major ethnic groups living in Senegal have in common that they attach value to virginity till marriage (Diop 1985: 97-144). ${ }^{3}$ This has been reinforced by the Islamization of ethnic customs, and by what is called 'wolofisation' of Senegalese society, i.e. the dominant and in many ways unifying influence of Wolof language and culture (Diouf 1998).

Although virginity is formulated in gender neutral terms, it has rather different meanings for girls and for boys. For girls, the norm of virginity is omnipresent and leaves them with little room to articulate their sexuality in a non-judgemental manner: sexually active girls are perceived as bad, weak, easy or materialist. During fieldwork, only three unmarried girls acknowledged to have had sex. Boys are not silent about their sexual experiences; on the contrary, they are proud of it. Men have to be goór, the Wolof word for man. A male who is a virgin and who is not sexually active is not goór. Being a man is not so much a matter of biology; it is not the fact of having a penis that makes a man a man, but what he does with that penis. Men become men by using their penis for heterosexual sex. ${ }^{4}$

The notion of virginity has to be understood as a socially constructed rather than a biological 'fact':

'The facts of life' refer basically to the biological facts of sexuality and reproduction. [...] When it comes to an analysis of sexuality and reproduction as social facts, these concepts are not, however, referring to biology, or nature, alone; they are loaded with a specific meaning, which by no means is given by nature itself. (Hastrup 1978: 49)

\footnotetext{
${ }^{2}$ Both Islam and Christianity identify marriage as the appropriate context for the expression of sexual feelings and acts. The religions however differ in their valuation of the sexual act and pleasure. Islam sees sexuality as enriching and enjoyable in itself, and does not connect it strictly to procreation. Celibacy is not held in great esteem, because suppression of sexual drives is considered dangerous for one's health. By contrast, Christianity sees sexual desire as a sin, and the desires of the flesh as threats to the spiritual order. Sexuality is only valued positively in relation to procreation, and it is immoral to break the connection between the two (through e.g. contraceptive use, homosexual sex, in-vitro fertilisation). Control over sexual drives and energies is highly valued in for instance celibacy (Jansen 2003).

${ }^{3}$ Some of the smaller ethnic groups, such as the matrilineal Busari, attach less importance to virginity.

${ }^{4}$ In hegemonic notions of masculinity in Senegal, homosexuality is seen as unacceptable and unmanly (Niang et al. 2003).
} 
This insight in virginity as a 'social fact' gains relevance in a context where it is questionable whether girls actually enter marriage as virgins. In order to fully grasp the meanings invested in this norm, a closer look at the wedding night is needed.

The wedding night - jéballe in Wolof - is a highly charged part of the marriage ceremonies. In Dakar, as in many other African contexts, the conclusion of a marriage is a long process covering several years and encompassing different stages (Diop 1985 97-144). One key stage is the religious marriage at the mosque-takk in Wolof - which is predominantly of Islamic origin, although elements of Wolof tradition are also present in it. A second key phase is the wedding night which is supposed to be the first sexual contact of the couple.

In the jéballe, a woman has to prove that she is a virgin and that she has not been penetrated before. The blood that a woman is supposed to lose during this first penetration is taken as the sign of her virginity. The next morning the aunts of the bride, in particular the paternal aunt (bàjjan), come to see the blood stain on the white sheet the bride has been laying on. When she is found a virgin, drums are played and griots sing to the honour of the woman and her family. The husband will give money to her parents and her aunts to show his appreciation. When the woman cannot prove her virginity and when the husband complains that he is not satisfied with her, the wedding night is unsuccessful. This can be a reason to dissolve the marriage. Besides the blood stain, which is the most important sign, a woman's virginity is also marked by the degree of difficulty for the man to penetrate the vagina and the weak condition of the newly wedded woman the morning after the wedding night. It is not relevant for the groom to prove his virginity. He has to prove his potency by penetrating his wife. A consummated marriage in combination with the tiredness and pain of the woman are taken as indicators of the man's virility and potency. If a man fails to penetrate the bride, the woman's family can dissolve the marriage.

During the complete marriage process, different payments are made by and to different people. Most are presented by the husband and his kin. A key payment is the alali farata, a sum of money paid by the groom to the girl to be married. The alali farata, 'which represents the real dot' (Diop 1985: 106; translation mine), is required for a valid marriage according to Islamic law and is also known as the Islamic sadâq (ibid.: 111). ${ }^{5}$ It is worthwhile to note that during the marriage process the relatives of the bride also receive substantial prestations. Female relatives, particularly the mother and bàjjan, are the main recipients in the ceremonies preparing for the consummation of the marriage and the wedding night itself. As recipients, the bride's mother and the bàjjan are stakeholders in the marriage process, and have an interest in safeguarding the virginity of the girl: they benefit materially and in status when the groom marries a girl of good character. It is interesting to note that the payments related to the preparation of the wedding night have recently gained in significance and have come to cover substantial amounts of

\footnotetext{
${ }^{5}$ In the literature and by Senegalese people, the term alali farata is commonly translated with the French term dot. The term dot literally means dowry, but can actually refer to different types of marriage payments. Whereas Goody proposes to label payments from the groom and his relatives to the bride herself as 'indirect dowry' (Goody 1973: 1-2), Jansen argues that the label of 'indirect dowry' adds to the confusion, and proposes to use the Islamic term sadâq or mahr (Jansen 1994: 112-116).
} 
money. In fact, the value of the dot is relatively modest (Diop 1985: 113-115; cf. Jansen 1994).

The wedding night has an important symbolic function in the unambiguous construction of the 'female' and 'male' identities of bride and groom:

A bride's defloration by penetrative sex is a ritual moment when, ideally, a 'real' man is potent and a 'real' woman is chaste, when gendered difference and hierarchy can be experienced as quintessentially real. [...] [In the wedding night defloration] an archetypal masculinity and femininity are created and revealed through interaction. Through the sex act, gendered identities and an act of domination are temporarily, but literally, embodied [...] In the return to everyday life, new, ambiguous identities emerge. (Lindisfarne 1994: 95, 91)

The wedding night differentiates women from men, and also transforms both bride and groom into gendered adults. The proofs that the wife and the husband have to deliver in the performative enactment of idealized gendered sexual identities reinforce each other: 'Virginity [...] is revealed by, and reveals, virility' (Lindisfarne 1994: 93). The bride's virginity marks the bride's status, but also that of her mother and bàjjan, her husband, and the marriage. Being a respectable woman also positively contributes to the power position of the wife in the household. The jéballe and the bride's virginity carry a load of social meanings and values, and affect the status and positions of a range of actors.

Many people in contemporary Dakar doubt whether girls actually marry as virgins, and some even state that you cannot find a single virgin girl anymore. Nevertheless, "virginity [...] may be ritually marked in circumstances which completely belie it or make its proof impossible' (Lindisfarne 1994: 93). Already in 1985, Abdoulaye-Bara Diop spoke of false proofs of virginity blood, and noted that the wedding night is widely practised, 'even though we do not have high hopes of [the virginity of the bride]' (119, translation mine). In contemporary Dakar, virginity is always being claimed (except in weddings of teenage mothers), even though nobody has many illusions about whether most brides really are virgins. Nobody openly dissociates her/himself from its importance, because the bride and groom as well as the bride's relatives have a vested interested in claiming virginity.

There seems to be a discrepancy between the tradition - that attributes a high importance to virginity — which we wish to respect, and the freedom of the girls of today. We make reference to symbols that pretend to refer to the same meanings as before. But they are either tricked deceptions, like the nuptial sheet, or purely formal, like the prix de la virginité. They do not carry any real meaning anymore apart from expressing the effort to apparently respect a past that, in fact, in many ways substantially differs from the present. (Diop 1985: 123; translation mine)

Young people simultaneously underline the value of virginity and are critical of the actual practice of the wedding night. The wish for discretion with respect to the stained sheet is partly the result of the influence of Islam, which according to opponents of the custom does not promote such an overt manifestation. It is also fuelled by 'a sort of modern pudeur', which is connected to growing individualism and a desire for intimacy in the couple (Diop 1985: 122). It has become popular to, 
so to speak, 'steal' the bride from the wedding reception and take her to, for instance, a hotel, where the newly wedded couple spends a few days away from the family's gaze.

\section{What girls do not talk about}

How prominent is virginity in the intimate lives of unmarried girls in Dakar? Consider the following discussion with a group of five in-school girls. We are discussing whether love can be a reason to sleep with a boyfriend:

Mariem: That cannot be an excuse! If you really, if you believe in God, and if you read the Qu'ran, there are certain things that every time, you should not do. You should not even try to imagine this or think about it. You think of your parents.

Aissatou: But me, if a boy asks me to have sex with him, I tell him 'no'. And when he comes back again...

Mariem: It is the last time.

Ramata: If I really love him...

Mariem: If I really love him, I will fight against that love.

Interviewer: And when you do not succeed in fighting it, in winning?

Mariem: I disappear.

Aissatou: I say to myself, if someone really loves you, he will not ask to sleep with you.

Mariem: Exactly!

Ramata: But sometimes, but sometimes...

Mariem: Sometimes what?

Ramata: But sometimes he loves you, but he asks to make love to him...

Mariem: So, he does not love you.

Ramata: Oh yes.

Mariem: No, no, no, it is very rare.

Ramata: It is rare, but...

Mariem: I, I say to myself, what do you do? Normally he shouldn't even say certain things. Normally, if he really loves you, he should not even ask you to sleep with him. Outside marriage, it is not normal. I say he does not love you. If he really loves you, he would have thought of your parents, or of the problems you will have with them afterwards.

Aissatou and Mariem dominate this discussion, as they have dominated most of the conversations. Aissatou always wears a veil, and this marks that she is an Ibadou and belongs to the relatively small group of Muslims who claim to practise the 'real' Islam. Mariem also attaches importance to religion, but like the majority of Muslim girls in Senegal is not veiled. ${ }^{6}$ The third girl, Ramata, is Muslim as well, but she is much less interested in religious matters. Mariem and Aissatou give voice to the

\footnotetext{
${ }^{6}$ Whereas veiling as it is commonly seen in Arabic contexts is only practiced by the Ibadous in Senegal, and not by the majority of Muslims, it is common for women to cover their head with a sjawl that matches their dress and is folded according to the latest fashion.
} 
dominant view that girls should not even think about sexual matters. It is very difficult for the other three girls in the group to voice a different point of view. Ramata is the only one who speaks up, but does not get much space to say what is on her mind. Ramata understands what Aissatou and Mariem are trying to say, but she is looking for space to see things differently. Her attempts to open up the norm, however, do not stand a chance.

This discussion clearly demonstrates the silencing with respect to female premarital sexuality. Prior to marriage, it is 'not normal' and should on no account take place. The discussion is illustrative of almost all conversations I had with girls about sex and sexual experiences. None of the 25 girls that participated in the focus group discussions admitted that they were sexually active, or even could be sexually active prior to marriage. In the individual interviews, only one girl acknowledged to have slept with her boyfriend. Apart from her, the only two other girls who talked about their premarital sexual experiences were teenage mothers, who could not deny having had sexual intercourse.

Somehow I felt that there had to be more to girls' intimate lives than this silence and denial of sexual experiences. For one thing, the silence of the girls did not match with the accounts of the boys, who spoke of engaging in sex with their girlfriend or other girls. Moreover, the non-verbal expressions of the girls themselves also left me puzzled with respect to their silence. The sexually suggestive movements of girls and women on dance events as the sabaar - which are a play of 'advances and retreats' (Heath 1994: 94) are obviously a sexual expression. The sometimes hilarious fun that girls and women had in dancing and the encouragement to try out suggestive movements points to the pleasurable side of female sexuality. In addition, women and girls have fun sharing seductive techniques. Senegal knows a market for seductive items including special incenses, bin-bins and different styles of sexy clothing and underwear (such as sexy lingerie, or crocheted pagnes worn under traditional dress). 'These products are said "to bewitch and turn men's heads", making them lose reason' so that men 'vibrate with pleasure' (Nyamnjoh 2005: 308, 300). There seemed to be more to female premarital sexuality than the silence and denial.

A look at statistics shows that indeed the reality of young people's lives does not always conform to the norm of abstinence until marriage. There is a discrepancy between the age of first marriage and the age of first sexual experience of women in Dakar. $^{7}$ The median age of first sexual experiences is 18.0 for both women and men (Enquête sur les comportements de prévention en matière de MST/SIDA dans la population générale de Dakar 1997: 26). For men, these sexual relations take place prior to marriage, since an almost ignorable percentage is married at the age of 20 (ibid.: 23). For married women, on the other hand, there is an age gap of 1 year between the median age of first sexual experience for women (18 years) and their median age of first marriage (19 years) (ibid.: xi, 24, 26). Although both the age of first marriage and of first sexual experience have been rising for women, the gap between them is also becoming larger (Enquête Démographique et de Santé au Sénégal 1997; Enquête sur les comportements de prévention en matière de MST/ SIDA dans la population générale de Dakar 1997). In fact, two thirds of the married and unmarried women in Dakar declare to be a virgin or to have been one at

\footnotetext{
${ }^{7}$ In those surveys, the term sexual experience is used in the narrow sense of heterosexual penetrative sex.
} 
marriage, which means that one third of the women loses her virginity before marriage (Enquête sur les comportements de prévention en matière de MST/SIDA dans la population générale de Dakar 1997: 32).

I want to be careful in the conclusions that can be drawn from those statistics, given that the reliability of reported sexual behaviours can be affected by the contentious character of the subject (Lagarde et al. 1995). Both limited sexual activity and underreporting can explain low figures of female premarital sex. By contrast, over-reporting is a risk for the data on men, given the pressures to be sexually active. Yet, these figures indicate that the ideal of abstinence till marriage is not brought into practice by the majority of the boys and a substantial part of the girls. This trend is also confirmed by data on pregnancies. In her exceptional study on fertility and early pregnancies of female adolescents in Senegal, Nafissatou Diop found that $29.8 \%$ of all first births were conceived prior to marriage: $12.5 \%$ were conceived before marriage, but born within marriage; $14.1 \%$ were conceived and born prior to marriage; and 3.2\% were to women who never got married after their pregnancy (1995: 89-91, 97). Pregnancies before marriage are not a new phenomenon. Nor are they an urban phenomenon; they occur as often in rural areas. It is only among the younger generations that they are more manifest in urban areas. In a study on a rural area in Senegal, Delaunay concludes that 'one out of six first births occurs to women who are still [unmarried]. In terms of conception, one out of four first births are conceived prior to first marriage' (Delaunay 1994: xxii). These two studies probably underestimate female sexual activity prior to marriage, as not all sexual encounters lead to a pregnancy. ${ }^{8}$

\section{Hypothetical case}

Because it was so difficult for girls to explicitly talk about their own sexual experiences, my assistant and I introduced a hypothetical story of a girl 'like them'. This girl had been seeing her boyfriend for some time. He was nice and caring, and did everything for her. When he asked the girl to sleep with him, she initially refused, but after a while she agreed. We asked the girls to explain why this girl accepted to have sex with her boyfriend.

Three reasons came forward as explanations for the girl's acceptance. Firstly, she agreed to having sex because she was afraid that she would lose the boyfriend if she refused. Secondly, she felt that she had to do something back for the presents and money that the boyfriend had given. Thirdly, she accepted, because she trusts the boyfriend and loves him. The way trust, love and confidence are linked to each other and to sex is rather complex. It seems simple: a boyfriend who cares has to help a girl preserve her virginity. Yet, love and sex are not necessarily in contrast with each other. A distinction has to be made between his and her love. A boy has to show that he loves a girl seriously; he does so by being attentive to her, and by not breaking up

\footnotetext{
${ }^{8}$ That sexual activity does not always lead to a pregnancy can be a matter of 'good luck', or because contraceptives were used or because sex did not take place during the fertile period in the menstrual cycle. Moreover, in early adolescence girls are not necessarily fertile at the moment their menstruation starts. Finally, given that the figures are based on living births, they underestimate the occurrence of premarital pregnancies by not taking pregnancies that ended in abortion into account (Diop 1995: 58, 98).
} 
the relationship when she initially refuses sex. The girl can on her turn prove her love by sleeping with him, but only when she is convinced of the boy's intentions. It is not either his love, or money, or her proof that explains why a girl accepts to sleep with a boyfriend. These different factors are part of an interconnected whole through which the meaningfulness of the relationship is constructed, that is, as serious rather than one 'for fun' to 'play around' in.

How much space do girls have to say 'no'? By threatening to end the relationship boys put girls under pressure. Moreover, with the 'sweet language' that boys speak girls are being tested to see if they have character or accept sex easily. Sometimes boys mean what they say, but sometimes they do not and only say what a girl wants to hear. Girls urge each other to be sceptical about boys' smooth talk. Girls have to learn to distinguish between a 'discourse of deceit' and one of sincere intentions. The pressure of the 'sweet language' used by boys does not make it an easy test for girls, but it would be too simple to argue that girls have no room to say 'no'. It provides them with the opportunity to establish themselves as a 'good girl'. Moreover, in this stage girls also test the boy to see whether he is serious and whether the relationship is worthwhile to continue. In the negotiations over sex, the gender identities of both the potent boy and the virgin girl have to be established, as a mirror to the performative gendered sexual identities in the wedding night.

When girls discussed the hypothetical story, there was momentum in the debate, in the sense that explanations were being repeated, reproduced and linked to each other. This indicates that it resonated with their life worlds and maybe even with their own sexual experiences. It is, however, interesting to note that the explanations of love, money, proof and pressure are always used when they talk about other girls, but are not valid for themselves. The reasons are strongly associated with the notions of 'loose', 'easy', 'weak' or materialist girls, and hence far too dangerous to apply openly to themselves. The explanations for accepting sex largely reproduce the restrictive dominant discourse, in which sex remains something 'bad' for unmarried girls. So, even though girls speak, the silence on female pre-marital sexuality remains intact.

This silence has to be placed in the context of the way boys categorize girls. With respect to love and sex, boys distinguish two types of girls: their 'real' girlfriend and the so-called 'easy' girls. The 'real' girlfriend is the girl that the boy claims to seriously love and care about. Drawing from idealized notions of love-which include elements of confidence, sharing, reciprocity, exclusiveness and fidelity (see van Eerdewijk 2006) boys claim that they do not 'touch the one they love'. Arguing that 'you only want the best for the girl you love', a boy cannot ask the girl he loves to misbehave. This respect for her is closely related to the girl's character: if she respects herself, the boy will also respect her. Character is also used to explain why boys relate to the category of 'easy' girls in a completely different way. Boys claim to have sexual relationships with this category of girls. They are considered 'easy' because it is assumed that they are without pudeur (modesty). The implication is that they are 'easily' convinced into sex. As she is not serious, boys will treat her accordingly: they amuse themselves with these girls. Boys characterize the relationships with 'easy' girls in terms of exchange relations: boys give a drink, presents of money, in exchange for which the girl accepts to have sex. The degree to which the money-sex exchange is made explicit varies from relation to relation, but it is never a straightforward commercial act or commodity exchange. Boys have to court 'easy' girls, and the more explicit the 
transaction element is, the more difficult it can become to convince the girl to have sex. It is important to acknowledge the difference between 'easy' girls and prostitutes. With the latter the commercial element is explicit.

It is tempting to consider the way boys speak about their relations with different types of girls as factual descriptions. This would however be incorrect, as boys do have sex with their 'real' girlfriend, and because the exchange relationship with the 'easy' girls is not as uncomplicated as suggested. Moreover, in real life it turns out to be very difficult to neatly classify girls in the two categories. The boys' typology of girls has to be read as an expression of the fragmented construction of male sexuality (cf. Nencel 1996): it allows them to experience their sexuality differently with different types of women. Read as discursive practices, the two categories of girls provide insight into the different sexualities boys are expected to enact. In the hegemonic construction, boys are expected to embody an active sexuality, in which they seek bodily satisfaction of their 'natural' and 'uncontrollable' desire. Boys are constructed as 'always in need' of and 'always ready' for sex. The doubts, embarrassment and insecurities in the boys' narratives, however, reveal a second norm to male sexuality, one in which boys have to be 'serious' and not too occupied with girls and sex. Boys have to be responsible with respect to their family, education and work, and should therefore put limits on their sexuality. In this sense, virginity and abstinence remain important reference points for male pre-marital sexuality. Boys hence embody two contradicting norms of male sexuality: a controlled and restrained sexuality with their 'real' girlfriends, and an active and instinctual sexual desire that needs to be satisfied frequently with the 'easy' girls (see also van Eerdewijk 2005). Obviously, these two contradict each other, and boys struggle in bringing these two together when shaping their sexuality.

The creation and circulation of the typology of girls is an important way through which Dakarois boys can reconcile these conflicting demands on their sexuality. The contradictory norms of male sexuality make that boys and men fragment their sexual desire. What is interesting to note here is that this typology makes that boys (and men) can redirect the tensions surrounding their gender and sexual identity - and thus their status as a person - to girls and women, whose female identities and sexuality are as a consequence subject to fierce societal surveillance and correction. Boys themselves do not take the heat, but in many ways remain outside the eye of the storm. Girls also categorize different types of boyfriends - the ideal boyfriend versus the undesirable, not-serious boys - but it is clear that in contemporary Dakar the typology of 'real' girlfriends and 'easy' girls has more impact on girls than a differentiation between ideal boyfriends and not-serious partners has on boys. The fragmentation of male sexual desire as such adds to the silence on female pre-marital sexuality. Yet, there are instances in which girls attempt to break the silence.

\section{Glimpses of pleasure}

A first opening can be traced in the following discussion with the same group of school-going girls as above. They are talking about out-of-wedlock pregnancies and Ramata points out that sometimes girls do have sex before marriage:

Ramata: But sometimes the girls do not do it on purpose ('pas express'), sometimes... 
Mariem: One day a friend told me she had slept with a boy and I was really surprised.

Ramata: But me, I think that she did not do that on purpose ('pas express').

Mariem: I say to myself, before doing certain things, you have to think, you have to think.

Ramata: But sometimes, she is just looking for fun and she does not think about the consequences.

Mariem: But you should always think about the consequences before doing it.

When Ramata argues that sometimes girls have sex unintentionally, she means that girls are not looking for sex, it just happens. One way to read the expression 'pas express' is that Ramata reinforces the norm of abstinence until marriage, but at the same time acknowledges a reality that can make it difficult to live accordingly. Girls can sometimes not say 'no'. Another way to read this phrase 'pas express' is as an attempt to give meaning to girls' sexuality outside the dominant judgemental discourse. She tries to define girls' sexual activity not so much in terms of its consequences, but in terms of its enjoyable aspects. A glimpse is seen of sex as something that is related to fun, and not merely to consequences and 'bad' behaviour.

In an indirect way, the term 'flirt poussé' also provides a glimpse of those pleasurable aspects. A 'flirt poussé' involves hugging, kissing, caressing, touching etcetera, but does not include penetrative intercourse. At one point Ramata called this 'faire l'amour avec limite', making love within limits. It is a compromise between not having sexual intercourse, and not leaving each other completely untouched, so to speak. The assumption is that both partners will not cross the line and stop before getting to actual intercourse. The reality is that these flirts can sometimes get out of hand, when partners get too excited. A 'flirt poussé' thus points to how the pleasurable and enjoyable aspects of sex can draw a girl into having intercourse. This reveals a so far silenced notion of sex as tempting and of girls' feelings of desire.

One girl who explicitly talked about pleasure in relation to sex was Ndèye, a 21year-old school-going girl who has a fiancé since a couple of years. During the interview, we talk about her first boyfriend, about her fears of the wedding night defloration, and about how religion asks her to abstain. When I ask her whether boys interest her, she complains that a lot of boys are only playing around.

Ndèye:... and when they come to the point that they want to have sex with me, they leave me. They think that I am an easy girl. The majority of the boys that I meet, they only want this one thing, sex. This first boyfriend to whom I refused to take my clothes off, he left me for that. I say to myself, if he really loved you, even if I refused, he should not leave me, but continue to see me. But he told me that if he asks me to sleep with him, and I refuse, then he will leave me. ... If you can accept, we can continue to see each other. If you refuse, it is over.

Interviewer: Why do they say that you are an easy girl?

Ndèe: Every time when they ask me to have sex with them, and if I accept, then they say that I am an easy girl. ... If I accept, they say I am easy.

Interviewer: If you accept?

Ndèye: They think I am an easy girl. They will say, that one, if one of us asks her, she will accept. The next day, he will say ... that girl, if you ask her, she accepts, 
she is very easy. And they will tell their friends that when they ask her, she will also accept, that I am very easy.

Interviewer: Did you have sex?

Ndèye: Yes, with my fiancé. (silence) But the thing that poses me with problems, is to take my clothes off in front of him.

Interviewer: What was it like, the first time?

Ndèye: There is some pleasure to it, it is pleasurable. ... He caresses me, he kisses me, and it is nice. (silence)

Interviewer: Did it hurt, the first time?

Ndèye: Hu? Not really, it did not hurt, not really.

Interviewer: Why did you accept with him?

Ndèye: I thought it was $\mathrm{OK}$, because he was my fiancé, and because he is going to be my husband. ... I accepted three times, but only with him. It is difficult to accept.

Interviewer: Why did you accept those three times?

Ndèye: Because he talks and talks too much. ... He says that I am his fiancé, that if God wants it, he is going to be my husband, that I should not be ashamed with him, that we are going to stay together, et cetera. He talks too much.

Interviewer: What did you think about it?

Ndèye: There is pleasure in it. It gives pleasure. ('Il y a du plaisir dedans, ça fait plaisir'.)

Interviewer: Did you regret it?

Ndèye: No. No regrets. But I am still embarrassed to do it. ... Maybe that will be different when I am more used to it.

For the largest part of the interview, Ndèye claimed that she had never been sexually active. When after almost an hour Ndèye told to have had sex, this comes out in a slip-of-the-tongue kind of way. She clearly uses the term pleasure to describe what it was like to sleep with her fiancé. During the focus group discussions that she participated in, she also expressed a notion of pleasure as a reason to engage in sex: 'at the moment that one makes love, it is to have pleasure in it that we do it. [...] We do it simply for pleasure'. Both Ndèye and Ramata give insight into a silenced world where sex is something (at least potentially) pleasurable for girls. It is not only the boyfriend's invitations that make it difficult for girls to refrain from sex, but also the sexual pleasure that they might find in it. In fact, pleasure might actually be a reason why girls are having sex.

Nafissatou and Penda confirm the importance of pleasure of sex for girls. Nafissatou is an unmarried mother of a 5-month-old son. She claims to have fallen pregnant the first time she slept with her boyfriend. I talk to her and Penda, one of her best friends. When discussing pornographic films and books ${ }^{9}$, Nafissatou indicates that they are useful because 'you can learn how to satisfy your guy without sleeping with him'. Nafissatou and Penda explain that being a virgin means not engaging in penetrative vaginal sex. Apart from vaginal penetration, everything is possible: 'you can touch the penis, you can caress it, you can suck it until you make

\footnotetext{
${ }^{9}$ Both Dakarois girls and boys use pornographic movies, books, magazines, websites as sources of information on sexual practices (van Eerdewijk 2007; see also Tadele 2006).
} 
him come, without penetration, yes that can go'. The two girls explain that there are different ways to satisfy your boyfriend while safeguarding your 'virginity'. The very narrow definition of virginity-preserving the hymen by not engaging in vaginal penetration - means that girls who claim to be virgins can actually engage in a range of sexual acts with their partner(s), including anal, oral and manual sex. This provides an escape for girls from the contradiction between the societal demand for female virginity and the reality of wanting to respond to the boys' sexual needs and the girls' own sexual desires. The creativity in defining sex and virginity suits the needs of girls. As Penda puts it: 'There are a lot of other good things [apart from penetration]. Luckily, otherwise we would not know what to do. [...] We cannot just stare at each other'.

Penda acknowledges that it is 'an advantage to know that you can do something else, that you can have pleasure, and the guy as well, without penetration'. The two girls indicate that they might feel that they want to protect their virginity, but when they are alone with their boyfriends, it is not easy to resist:

Penda: Sometimes, you, you want to ... your body does not leave you at ease, you know.

Nafissatou: We need it.

Penda: There is nothing you can do, you know. You want to resist, but there is nothing you can do.

The bodily desire for sex thus comes forward as an important reason why girls cannot abstain. And satisfaction of this sexual pleasure is also important:

Penda: I think that this thing has to be shared, you know.

Nafissatou: Right, it has to be shared. (we all laugh)

Penda: I think that the boys, them, it is selfishness; they come in the first place.

You have to do everything to please them. Afterwards, the girl, she comes afterwards, you know.

Interviewer: But is it important, when you have a boyfriend, that he tires himself to give you pleasure?

Penda: Yes, yes, it is important.

Nafissatou: It is important.

The two girls say that some boys make an effort to satisfy the girl, while others do not really bother. They agree that 'it is not interesting' when the boy does not respond to their needs. When the girl takes the time to give him pleasure, it is 'frustrating' when he just stops there. This illustrates not only the sexual needs girls (can) have for sex, but also their desire for sexual satisfaction and pleasure.

\section{Silence, pleasure and agency}

Summarizing my empirical findings, the dominant narrative on the sexual lives of unmarried Dakarois girls, which is also produced and reproduced by the girls themselves, renders engaging in sex before marriage unacceptable and values virginity for giving dignity and honour. Sexuality is either denied or put in negative terms, sexual pleasure seems to be absent and silence predominates with respect to 
girls' sexual agency. When listening carefully and reading between the lines, the enjoyable aspects for girls of sex can be heard. Sex can be something pleasurable, and girls also turn out to experience bodily desires and sexual needs. They not only have sex in response to the needs and demands of men, but also engage in sex out of their own needs and because it gives them pleasure.

Against this background, I can formulate three conclusions with respect to the agency girls have or lack in sexuality. To start, Abu-Lughod has argued that women's denial of their sexuality can be interpreted as an active act of deference, through which women become subjects in the existing social order (Abu-Lughod 1986: 118-167). Girls are not merely subordinated by dominant discourses, but are also agents who actively (re)produce and reinforce them. Moreover, compliance to and confirmation of dominant gender identities, however restrictive and silencing they can be, can provide the room for manoeuvre in which deviations can be enacted. Initially, girls have to refuse sex in order to embody that ideal of 'a respectable girl', after which they can take up space in which they can engage in sex, either penetrative or other. In a similar way, boys first have to establish themselves as 'serious' and trustworthy, before girls have sex with them. Girls are agents in this process of mutual testing.

Secondly, female sexuality might be caught within a male-centred construction of heterosexuality, but this does not leave women and girls without agency. Although it is directed towards the male needs and pleasure, girls do have agency in being seductive and sexy, and in satisfying their partner. In Senegal this means that, amongst others, women encourage each other to be masters in sexually pleasing their 'man', and this also enables women and girls themselves to enjoy sexuality. Moreover, as men are dependent on their acceptance or refusal to take up this role, girls and women also have power. They can use their capacity to refuse or accept to their own advantage. In her study in Tanzania, Silberschmidt notes that sugar-daddy relationships are 'not a one-way exploitation', but that the girls are 'active social agents, entrepreneurs who deliberately exploit their partner(s)' (Silberschmidt 2001: 1822). So, within the male-centred and male dominated construction of female heterosexuality, women are not just passive objects, but exercise agency.

Finally, when considering sexual agency, the crucial question is whether girls can express their sexuality in a way that is not mainly directed towards male satisfaction and pleasure. The girls in the Tanzanian study 'did not consider sex as an activity by which their own sexual needs would be met' (ibid.: 1822). For the Dakarois girls, sex-partly-originates from and is directed towards their own sexual needs and pleasure. As such, there is female sexual agency. Satisfaction of their needs is not always nor easily realized because boys and men put themselves in the first place.

Female pre-marital sexuality, and in particular girls' agency, cannot be understood in a one-dimensional way. Gendered sexuality is multi-layered and its different, sometimes contradictory, dimensions have to be taken into account to do justice to girls' experiences. Such a multi-dimensional perspective sheds light on the coexistence of silence with sexual pleasure and female agency. A crucial step in seeing the almost invisible reality of girls' sexual lives is to question the meaning of the terms 'having sex' and 'virginity'. It turns out that these have very specific and narrow definitions, concentrating on penetrative vaginal sex. In this constellation of meanings, virgin girls can have an active sexual life, practicing a range of sexual 
acts. This underscores the need to scrutinize the concepts of sex and sexuality in research.

The acknowledgement of the co-existence of silence, pleasure and agency allows for a more nuanced and more dynamic picture of the power processes in sexuality and intimate relationships. The policy relevance of this multi-dimensional understanding is that girls' safe sex behaviour, or maybe the lack thereof, is shaped in a context in which they reproduce dominant restrictive notions of female premarital sexuality and deny their sexual agency, and simultaneously deviate from this norm by acting on their sexual needs and desire by looking for pleasure in sex. The promotion of safer sex falls into these dialectics of gendered sexuality, and therefore has to take confirmations to dominant norms as well as deviations from it into account. The acknowledgement of female pleasure and sexual agency co-existing with their silencing requires a rethinking of reproductive health and AIDS prevention policies. Rather than promoting abstinence and giving women power to say 'no', 'as if the only problem was to lead astray the annoyance of men', (Spencer 2000: 126, translation mine), the sexual desire of women has to be recognized, 'particularly the fact that she might also desire penetration' (ibid.). It is crucial to develop strategies that can build on girls' and women's agency to make them have safer sex when they say 'yes'. They should for instance seek to address nonpenetrative types of sex, and assist girls and women in protecting those acts. Approaching girls and women in such a dynamic and multi-dimensional perspective also necessitates a critical approach towards the way boys experience and construct their male pre-marital sexuality in their daily lives.

Open Access This article is distributed under the terms of the Creative Commons Attribution Noncommercial License which permits any noncommercial use, distribution, and reproduction in any medium, provided the original author(s) and source are credited.

\section{References}

Abu-Lughod, L. (1986). Modesty, gender, and sexuality. In Veiled sentiments: Honor and poetry in a Bedouin society (pp. 118-167). Berkeley: University of California Press.

Delaunay, V. (1994). L'entrée en vie féconde: Expression démographique des mutations socioéconomiques d'un milieu rural sénégalais. Paris: Centre Français sur la Population et le Développement.

Diop, A. -B. (1985). La famille Wolof. Paris: Karthala.

Diop, N. J. (1995). La fécondité des adolescents au Sénégal. Dakar: Union pour l'Etude de la Population Africaine.

Diouf, M. (1998). Sénégal: les ethnies et la nation. Dakar: Les Nouvelles Editions Africaines du Sénégal.

Enquête Démographique et de Santé au Sénégal (1997). Dakar: Ministère de l'Economie, des Finances et du Plan.

Enquête sur les comportements de prévention en matière de MST/SIDA dans la population générale de Dakar (1997). Rapport d'analyse. Dakar: Ministère de la Santé et de l'Action Sociale \& ONUSIDA.

Goody, J. (1973). Bridewealth and dowry in Africa and Eurasia. In J. Goody \& S. J. Tambiah (Eds.), Bridewealth and dowry (pp. 1-58). London: Cambridge University Press.

Green, G., Pool, R., Harrison, S., Hart, G. J., Wilkinson, J., Nyanzi, S., \& Whitworth, J. A. G. (2001). Female control of sexuality: Illusion or reality? Use of vaginal products in south west Uganda. Social Science and Medicine, 52, 585-598. 
Hastrup, K. (1978). The semantics of biology: Virginity. In Sh. Ardener (Ed.), Defining females: The nature of women in society (pp. 49-65). London: Croom Helm.

Havard, J. -F. (2001). Ethos 'bul faale' et nouvelles figures de la réussite au Sénégal. Politique Africaine, $82,63-77$.

Heath, D. (1994). The politics of appropriateness and appropriation: Recontextualizing women's dance in urban Senegal. American ethnologist, 21(1), 88-103.

Holland, J., Ramazanoglu, C., Sharpe, S., \& Thomson, R. (1998). The male in the head: Young people, heterosexuality and power. London: Tufnell.

Hoskins, B. (2000). Young women's sexuality: All bad news? Feminist Review, 66, 142-146.

Ingham, K. (1990). Senegal: Unity in diversity. In Politics in modern Africa: The uneven tribal dimension (pp. 115-134). London: Routledge.

Jansen, W. (1994). Symbolische omkering van huwelijksgeschenken in Algerije. In H. Driessen \& H. de Jonge (Eds.), In de ban van betekenis: Proeven van symbolische antropologie (pp. 112-140). Nijmegen: SUN.

Jansen, W. (2003). Religie, seksualiteit en vrouwen: een vergelijking tussen islam en christendom. In P. van Tongeren \& G. Steunebrink (Eds.), Vreemde verwanten: Overeenkomsten en verschillen tussen islam en christendom (pp. 100-121). Nijmegen: Valkhof Pers.

Lagarde, E., Enel, C., \& Pison, G. (1995). Reliability of reports of sexual behavior: A study of married couples in rural West Africa. American Journal of Epidemiology, 141(12), 1194-1200.

Lindisfarne, N. (1994). Variant masculinities, variant virginities: Rethinking 'honour and shame'. In A. Cornwall \& N. Lindisfarne (Eds.), Dislocating masculinities: Comparative ethnographies (pp. 8296). London: Routledge.

Mills, S. (1997). Discourse. London: Routledge.

Nencel, L. (1996). Pacharacas, putas and chicas de su casa: Labelling, femininity and men's sexual selves in Lima, Peru. In M. Melhuus \& K. A. Stølen (Eds.), Machos, mistresses and madonnas: Contesting the power of Latin American gender imagery (pp. 56-82). London: Verso.

Nencel, L. (2004). Heterosexuality. In Ph. Essed, D. Th. Goldberg, \& A. Kobayashi (Eds.), A companion to gender studies (pp. 132-142). Oxford: Blackwell.

Niang, Ch. I., Tapsoba, P., Weiss, E., Diagne, M., Niang, Y., Moreau, A. M., Gomis, D., Wade, A. S., Seck, K., \& Castle, C. (2003). 'It's raining stones': Stigma, violence and HIV vulnerability among men who have sex with men in Dakar, Senegal. Culture, Health and Sexuality, 5(6), 499-512.

Nyamnjoh, F. B. (2005). Fishing in troubled waters: Disquettes and thiofs in Dakar. Africa, 75(3), 295324.

Shefer, T., \& Foster, D. (2001). Discourses on women's (hetero)sexuality and desire in a South African context. Culture, Health and Sexuality, 3(4), 375-390.

Silberschmidt, M. (2001). Adolescent girls, illegal abortions and 'sugar daddies' in Dar es Salaam: vulnerable victims and active social agents. Social Science and Medicine, 52, 1815-1826.

Spencer, B. (2000). La femme sans sexualité et l'homme irresponsable. In Ch. Verschuur (Ed.), Quel genre d'homme? Construction sociale de la masculinité, relations de genre et développement (pp. 121-130). Genève: Institut Universitaire d'Etudes du Développement.

Tadele, G. (2006). Bleak prospects. Young men, sexuality, and HIV/AIDS in an Ethiopean town. Leiden: Africa Studies Centre (Research Report 80).

van Eerdewijk, A. (2005). Being a man: Young masculinities and safe sex in Dakar. In T. Davids \& F. van Driel (Eds.), The gender question in globalization: Changing perspectives and practices (pp. 59-73). Aldershot: Ashgate.

van Eerdewijk, A. (2006). What has love got to do with it? The intimate relationships of Dakarois girls. Etnofoor, XIX(1), 41-62.

van Eerdewijk, A. (2007). The ABC of unsafe sex: Gendered sexualities of young people in Dakar (Senegal). Nijmegen: Radboud University Nijmegen (PhD Thesis). 